Revista de Ensino em Artes, Moda e Design

Dossiê 6

A modelagem integrada ao projeto de Moda no âmbito do ensio

\title{
A ARTE DA PEPRFORMANCE COMO AÇÃO CULTURAL NA ESCOLA PÚBLICA: ALGUMAS EXPERIÊNCIAS E OS SENTIDOS DA SUBVERSÃO NO UNIVERSO ESCOLAR
}

Performance art in the public school: study about subversion in the school 1environment

El arte del performance como una acción cultural en la escuela pública: algunas experiencias y los sentidos de la subversión en el universo de la escuela

Thiago Camacho Teixeira ${ }^{1}$

${ }^{1}$ Doutorando e mestre em Artes Cênicas pela ECA-USP. Graduado em Arte-Teatro pela UNESP. Licenciado em Letras - Português, Inglês e Literatura pela UNIP. É ator, performer, professor de artes, teatro, literaturas e línguas e membro do grupo de teatro e performance Desvio Coletivo. Lattes: http://lattes.cnpq.br/2862772073228990 | Orcid: https://orcid. org/0000-0001-9890-577X | E-mail: thiagocamacho@usp.br. 


\title{
Resumo
}

Este trabalho apresenta apontamentos teóricos, metodológicos e práticos sobre construções cênicas próprias da linguagem da performance, elaboradas por meio de experiências estético-sensoriais, seus decorrentes relatos e repercussão no interior de escolas públicas localizadas dentro de uma periferia da Zona Sul da cidade de São Paulo/SP. Contempla ainda o diálogo entre artistas, inclusive em formação, comunidades escolar e local, professores, estudantes e sociedade. Enxergando a arte da performance como linguagem e considerando suas tendências transgressoras, o intuito é discutir os sentidos da subversão, em seu sentido literal e simples, em significado mais metalinguístico do que histórico, como um componente próprio da performance no ambiente escolar.

Palavras-chave: Performance; Subversão; Escola pública.

\begin{abstract}
This text presents theoretical, methodological and practical notes on performance-specific scenic constructions, elaborated through aesthetic-sensorial experiences, their reports and repercussions in the interior of public schools located in the interior of a periphery of the South Zone of the city of São Paulo-SP. It also contemplates dialogue between artists, including in training, school and local communities, teachers, students and society. To view an art of performance as language and to consider her like transgressive tendence, the intention is to discuss the meanings of subversion, in the literal and simple sense, in a metalinguistic form, and as a component of school performance education environment.
\end{abstract}

Keywords: Performance; Subversion; Public school.

\section{Resumen}

Este artículo presenta notas teóricas, metodológicas y prácticas sobre construcciones escénicas propias del lenguaje del performance, elaboradas a través de experiencias estético-sensoriales, sus informes resultantes y sus repercusiones dentro de las escuelas públicas ubicadas en una periferia de la zona sur de la ciudad de São Paulo-SP. También contempla el diálogo entre artistas, incluso en formación, escuelas y comunidades locales, docentes, estudiantes y la sociedad. Al ver el arte del performance como lenguaje y considerando sus tendencias transgresivas, la intención es discutir los significados de la subversión, en su sentido literal y simple, en un sentido más metalingüístico que histórico, como un componente apropiado del performance en el entorno escolar.

Palabras-clave: Enseñanza superior; Moda; Curriculum. 


\section{INTRODUÇÃO'1}

Através do relato de vivências em performance em uma escola pública da periferia da Zona Sul de São Paulo-SP, este artigo apresenta o pesquisador, professores, estudantes, comunidade escolar e local, e mais amplamente a sociedade como espectadores, agentes interventivos ou propositores em um processo de construção coletiva de experiências práticas de comunicação e expressão. A partir de reflexões e observações sobre a arte da performance como linguagem e suas tendências transgressoras, experimenta-se o questionamento sobre os sentidos da subversão. Também destaca como a textualidade cênico-poética pode ser substanciada a partir da estética da ressignificação e do embate de ideias.

Metodologias, fundamentações teóricas e práticas sobre construções cênicas da performance trazem à tona, por intermédio de relatos e repercussão, reflexões sobre os limites institucionais, as formas de controle da liberdade de expressão e sobre a subversão como componente dessas manifestações artísticas contemporâneas a partir de seu espectro sócio-político-cultural. O termo subversão foi utilizado em seu sentido literal e simples, a partir de um significado mais metalinguístico do que histórico, a fim de caracterizar o objeto da análise.

Ainda contempla o diálogo entre artistas, comunidades escolar e local, professores, estudantes e sociedade. $O$ intuito é discutir os sentidos da subversão, um componente próprio da performance no ambiente escolar. Apresenta uma vivência do questionamento sobre seus sentidos, a partir de reflexões e observações sobre a arte da performance como linguagem e suas tendências transgressoras.

\section{SENTIDOS E HISTORICIDADE DA TRANSGRESSÃO E DA SUBVERSÃO}

Este artigo e experimentos referem-se à passagem de tempo entre 2014 e 2020, destacando comentários e visões de mudanças políticas e de governo e sua relação com as Estéticas e rupturas artísticas: uma análise de mudanças temporais e ideológicas do período que afetam a arte da performance no Brasil. Há na passagem do tempo uma efemeridade notável na visão de alguns pesquisadores acerca da linguagem da performance no Brasil. Ela vem se destacando como algo a ser evitado, especialmente em ambientes de educação. Se, no intervalo entre os anos pós-ditadura e os anos 2000, essa linguagem passava despercebida no sentido ameaçador ou até se confundia com as artes teatrais dramatizadas, atualmente fazer performance incorre diretamente em contraversão, isto é, algo mais definido quando se faz um juízo de valor popular e ideológico. A sensação de um performer na atualidade, segundo relatos de professores e estudantes nas universidades, é de que sua atividade subjetiva está sendo controlada, por vezes, censurada. Seria como fazer algo errado. Há então algumas semelhanças entre o plano político macro da Ditadura Militar Brasileira (1964-1985), que cerceava a liberdade de expressão, e a sensação de criminalização da performance. Não há mais dúvidas sobre os intentos governamentais de apologia ${ }^{1}$ O artigo é uma versão adaptada da dissertação de mestrado do autor, intitulada "A Arte da
performance na escola pública: Estudo de casos sobre a subversão no ambiente escolar". 
aos períodos ditatoriais e nem sobre a sensação de criminalização de uma linguagem cuja essência é composta por transgressão e subversão.

Essa sensação de criminalização é um sintoma evidente. Projetos políticos como o Escola sem Partido ou partidos políticos propriamente ditos (Partido Social Liberal - PSL, ligado de todas as formas ao atual presidente Jair Messias Bolsonaro), de modos ideológico e político, ou movimentos híbridos de investida político-econômica, tal como o Movimento Brasil Livre - MBL, todos de orientação neoliberal, têm preconizado uma escola que forme para o trabalho ao invés de para o pensamento autônomo e criticamente proponente. Forma-se não para que se discuta ou debata cada vez mais sobre formação de conceito social, de progressão da consolidação de direitos, entre outros atributos que desenvolveriam melhor uma democracia que se deseja plena. Ao projetarem uma escola majoritariamente conteudista, traçam a tiracolo a dissolução contínua das ideias críticas que poderiam ensejar transformações nos espaços e tempos de nossa sociedade em crise. Crise? Sim, não basta olhar ao redor e extrair disso amenidades, pois quando o costume é continuamente de indiferença à violência, à miséria, à injustiça, aos horrores sociais que são praticados em uma nação assoberbada por escândalos de corrupção, por desigualdades sociais abismáticas e pelos crescentes empobrecimento e negação da cultura, parece natural que isso se arraigue e faça parte da paisagem comum.

[...] temos por analisar a ideia de progresso subjacente às noções de ruptura e vanguarda. O pensamento e os ideais modernistas são questionados no pós-modernismo, que expressa o fim dos manifestos e das utopias. Um mundo sem fins transcendentes, sem ideais superiores, um mundo técnico é o resultado desses desmoronamentos. Esta incapacidade actual de se indicarem trajectos ou destinos parece resultar da multiplicidade contemporânea de experienciar o mundo de forma artificial, que as novas tecnologias estão a potenciar. Parece igualmente impossível encontrar um artista modelo à maneira de Baudelaire, que aponta um Sr. G, Pintor [como protótipo] da Vida Moderna. (CORREIA, 2010, p. 2-3).

A modernidade está e permanece nesta abordagem porque buscamos como referências as rupturas que marcaram sua passagem. Ela tem o impacto do novo. Quando chamamos algo de moderno, ainda que no senso comum, esse objeto de análise se caracteriza como algo especialmente diferente, e, por isso, inovador. A performance eclodiu desse território: instável, conturbada e proponente. E ainda hoje, na contemporaneidade, ela mantém seu carácter subversivo nas propostas. Portanto, não falaremos de performance sem recorrer ao modernismo ou aos períodos imediatamente anteriores e importantes, justamente porque deles ela advém, em contextos muitas vezes semelhantes.

Quando termina o período vanguardista moderno, resta, na contemporaneidade, o fôlego de poucos arcabouços da linguagem que preservam e herdam a natureza da ruptura crítica; entre eles, o que emerge do terreno movediço da linguagem em performance. Quando uma ação cultural tende a esse movimento, ela é tida como estratégia de inimigos públicos, algo a se combater, como no passado. No período moderno, assim como no contemporâneo, temos a reatividade conservadora para com as artes, como podemos constatar na performance La Bête, de Wagner Schwartz (BRUM, 2018), quando um homem nu, no caso o próprio artista, foi assunto 
nacional quanto à discussão da presença de uma criança na exposição. Ao imaginário geral, essa forma estética muitas vezes aparece como um acontecimento a temer ou como indicativo de uma degeneração moral, algo que pode ser proveniente de ideários construídos por tempos de lideranças, como dito, reativas e conservadoras. Então, performance como "um modernismo" controverso, e como aquilo que não se pode aceitar, torna-se um alvo: um clamor popular reivindica a criação de leis que impeçam essas atividades, como fazem alguns movimentos neoliberais na política brasileira. Aparentemente, o que se deseja em coralidade é que os performers sejam presos, agredidos, torturados ou mortos. Isso pode ser constatado nos comentários das páginas do Desvio Coletivo ou da performer Priscilla Toscano no Facebook, esta ameaçada e perseguida devido à sua ação performativa, quando a mesma se manifesta politicamente defecando, na Avenida Paulista, na fotografia de Jair Messias Bolsonaro (MKS, 2016), na época (2016) deputado federal e atualmente presidente. Os performers são, então, ameaçados, perseguidos e também violados, porque a moralidade local entende que assim se deve fazer.

Endemonizada por religiosos conservadores ligados a esses movimentos, por igrejas neopentecostais interessadas em lucrar com a aparência de oposição àquilo que assusta o povo, angariando números, pessoas, mentes e 'bolsos', a linguagem em voga ganha a aparência do mal. O contraditório é coibido. Por isso, esse tipo de ação cultural passa a cair nos espaços como uma bomba, como um atentado - tal como no contexto de escândalos vistos na gênese da arte moderna - vide semana de 1922 (SCHILLING, 2019). A ação cultural passa então a ser atacada a partir de uma citação proposital, como, por exemplo, desviar o foco e dissuadir protestos contra a Reforma da Previdência (debates entre 2018-2020).

Mas os que mais chamam a atenção são, talvez, os próprios artistas e o seu silêncio - silêncio aqui pode significar atitudes sem efeito. Eles acomodam sua produção em um plano parecido com o instalado politicamente, que vou chamar de "plano dos limítrofes": seguem as orientações verticais da ideologia dominante e não se atrevem a ultrapassar esses limites, sejam morais, burocráticos, institucionais etc.

Falando-se em instituição, a escola pública, lócus desta pesquisa, está repleta de regras sobre o que os estudantes, menores de idade, podem aprender e apresentar, sobre que assuntos podem ser abordados etc., ao ponto do Projeto Escola sem Partido (movido pelo PSL e MBL) tentar reprimir a opinião sócio-política dos professores em suas aulas (SALDAÑA; FARIA, 2018). Repletos de papeis a preencher, os professores não têm tempo ou valorização adequados, enfrentam violências, muitas vezes físicas, deparando-se com vulnerabilidades que tornam o ensino-aprendizado e os espaços de produção de cultura completamente improcedentes, e isso raramente é discutido de modo satisfatório. A burocracia, os automatismos e a ausência da reflexão proporcionam um espetáculo de desânimo, insatisfação e falta de esperanças.

Em conversa com a professora Lúcia Corsi, efetiva na Escola Estadual República do Panamá, rede estadual de São Paulo (2018), e pós-graduada em educação, ela nos diz que "nunca se sente valorizada por seus esforços, formações, salários, que são muito baixos, e que ainda aguenta precariedades como salas de aula lotadas, violências de pais e alunos e da gestão da própria escola que funciona de modo empresarial, neoliberal, sem vistas voltadas à flexibilidade, ao humanismo e à lógica própria 
da educação." Reafirma ainda que "educação não são números e metas a cumprir simplesmente, que não se pode negligenciar o processo rico da experiência, do âmago do sentir, que não estão ligados somente aos resultados para o Estado conquistar verbas e para o governo dizer que fez algo através de planilhas".

Já os artistas, mesmo os mais ajustados ao que o sistema impõe por ideologia ou mesmo opressão, acabam se afastando dos ambientes de formação. Não se trata de uma generalização, mas, quando ressurgem, raramente trazem consigo a disruptura - que, ao invés de distrair, faz pensar -, pois já estão tolhidos, já foram censurados ou mesmo impedidos. Quem nunca ouviu as expressões "É difícil viver de arte no Brasil", "Os professores são muito mal pagos" ou "Não conheço um só professor que já não tenha sido desrespeitado, agredido verbalmente ou fisicamente em sala de aula, nas escolas públicas"? (MARTINS, 2019). São frases recorrentes e indicativas de uma situação constante: a desvalorização da educação e da arte, submetidas a esse tipo de relação. Como nos salientou Lúcia: "Não temos mais liberdade de expressão em sala de aula, porque somos impedidos pelo medo, são pais, alunos, gestão escolar e a sociedade colocando o peso da represália e do processamento jurídico em cima de nós". É neste tipo de ambiente que se quer coibir o debate sobre violência, bullying, identidade de gênero, respeito às diferenças e combate às desigualdades sociais. É neste ambiente que se deseja encerrar as manifestações artísticas e culturais, ou mesmo o ensino de artes (TOKARNIA, 2018).

É em tal contexto que o artista aparece: em um plano de limítrofes. Quando sua ação se torna alvo político, é mal falada, mal vista, considera-se que a ação "deu errado", mas é justamente o contrário: a indigestão causada pela performance indica que ela funcionou, pois muitas vezes opera exatamente pelo incômodo. Como uma linguagem de virulência transformadora e de confrontos morais, de origens subversivas, ela remexe no íntimo, em valores enraizados. Então por que ainda se espera o sucesso propriamente dito de uma performance com base em sua neutralidade? Por que ainda se espera que ela dê certo a partir de elogios que atestam a sua efetivação? Natural seria se uma boa performance revirasse o estômago e estremecesse os imaginários consolidados que perpetuam injustiças sociais, ou mesmo particulares, ou que ao menos causasse incógnitas sem respostas prontas, uma vez que o papel deste tipo específico de linguagem está associado diretamente ao questionamento, ao âmago do sentir, e de promover perguntas que proporcionem o desenvolvimento do que se entende por formação.

Assim, a partir destas reflexões, podemos atribuir sentidos diferentes aos termos transgressão e subversão. Tal como ocorre com a performance, as definições destes termos também são instáveis e movediças. Por isso, aqui devemos utilizar algumas diferenças práticas substanciais citadas por alguns autores em análise de caso, quando assim os definem.

Os novos posicionamentos ultrapassam literalmente a impostura das instituições, a violência policial, o esvaziamento das relações sociais. E tudo isso em direção a um tempo, como diria José Américo Motta Pessanha, "marcado pela ênfase dada às noções de ruptura, de diferença, de pluralidade". Segundo Pessanha, os traços da contemporaneidade vislumbram tout court as categorias "de multiplicidade, de corte, de alteridade". Com o pronunciar dessa alteridade é todo um autoritarismo social que se vê combalido, ou ao menos 
ultrajado. A regulação dos poderes e direitos sociais muitas vezes instaura na tarefa da lei, como salientou Marilena Chauí, "a conservação de privilégios e o exercício da repressão". Segundo a autora, "Por esse motivo, as leis aparecem como inócuas, inúteis ou incompreensíveis, feitas para serem transgredidas e não para serem transformadas". (PAZ et al., 2016, p. 61).

Tais diferenças que permeiam a semântica destas palavras, quando as tratamos no campo da performance como linguagem, remontam o seu próprio terreno historicizado: a performance que pode transgredir mas não subverter. Ou especialmente o que vou chamar de "novo performer", aquele que performa sem incomodar, sem protestar, sem demonstrar o que sente de ruim ou de bom com autenticidade e toda a potência do âmago do sentir, porque os limítrofes sociais e ideológicos os bloqueiam. Neste caso, o mesmo nem subverte e nem transgride. Não se trata de criticar uma expressão sem viés crítico, mas de chamar atenção para o fato de artistas estarem sendo censurados e pessoas quererem se expressar e não conseguirem. Elas estão bloqueadas pela cultura consciente ou inconscientemente. Como dito, tais bloqueios - de natureza moral, burocrática, institucional etc. - acarretam uma produção sempre em conformidade com o sistema dominante vigente, consequentemente ao seu próprio "superego", e nunca conforme os anseios e as necessidades subjetivas do artista ou não artista, o que descaracteriza e transforma no tempo a natureza de uma linguagem que em sua atmosfera de origem tinha a estética da ruptura.

A manifestação de sentidos precisa estar em consonância com as ordenações verticais do poder concentrado e com a estabilidade intrapessoal para ser considerada promissora, ou um sucesso, enquanto seu fracasso é medido pelos níveis de crítica. Parece que atualmente os corpos se abstiveram de memória ou da capacidade de consultar historicamente os catálogos, registros e ocorridos - por exemplo, a respeito da imanência da performance como uma emissão subversiva ligada e nascida nas vanguardas da modernidade.

$\mathrm{Na}$ lógica dos poderes espalhados, em que se percebe uma manifestação de poder em cada espaço, existe também uma voz dissidente e que opera as formas resistentes contra cada um dos mesmos. Cada lugar possui então uma ordem dominante e uma oposição resistente a ela. Os tempos de micropolíticas são os tempos de microestruturas de poder sendo enfrentadas por microrresistências em todos os espaços, e não mais a partir de um embate entre poderes duais macroestruturais, como na Guerra Fria (quando havia capitalismo versus comunismo nas esferas econômica, política, social e cultural). Isso significa que uma micro- resistência pode confrontar e alterar uma realidade localizada, conflitar a partir de problemas políticos, sociais ou culturais inerentes às condições e suas consequentes reivindicações específicas dentro daqueles limítrofes de curto espectro. Também indica que, exatamente por estarem todos concentrados individualmente ou em coletivos circunscritamente menores ou de dimensões encolhidas, tornou-se muito mais difícil desestruturar uma ordem dominante maior que subjuga e orquestra todas as outras micropolíticas. Neste sentido, a arte, ainda que negando a si mesma, na chave da antiarte, passou a ser transgressora no sentido local e não mais subversiva no sentido macroestrutural. Trata-se da arte que transgride sem alcançar nenhum efeito sistêmico da ampla re- 
alidade vigente. É a arte que não subverte porque todos os espaços estão ocupados por micropolíticas transgredidas, os ditos problemas locais que não deixam mais espaço para questionamentos de estrutura global. Neste sentido, para ser controversa ao ponto de ser subversiva, a arte necessitaria não só transgredir regras isoladas, mas perturbar uma ordem maior, como a moral de uma nação, ou uma moral histórica, de tradições, sejam familiares, econômicas ou outras de relevância enraizada. Isto é, mudar algum conceito de ética, sua burocracia, deflagrando suas falhas e a manutenção que faz pelo que se quer alterar. A transgressão pode até infringir uma lei, mas não altera a Constituição. Embora não haja problema nisso, pois a transgressão local tem também o seu valor, assim como não transgredir.

Quando uma forma artística surge com uma contestação abrupta, por meio da subversão, ela logo é identificada como tal porque sistemicamente vai causar escândalos midiáticos, censura, punição dos autores, perseguição, ameaças e tudo que temos visto e falado acerca disso. A subversão é ameaçadora porque, sem transgredir nenhuma lei, pode se pretender a alterar a própria Constituição. Muda a realidade dos indivíduos de um modo geral, isso quando não a revoluciona. Foucault fala de transgressão com este mesmo sentido.

[...] deve-se considerar ainda que essas intervenções não raro são suscetíveis de contraposições, conflitos, censuras, violências e criminalizações. Os casos de obras que foram censuradas durante as ditaduras militares, ou daquelas censuradas por questões morais e/ou religiosas nos países latino-americanos são aqui exemplares. Em tempos de crise, de segregação e preconceitos, de arrogância, de guerras de poder, de intolerância e manipulação dos meios de comunicação, percebe-se que esse debate vai além de discussões sobre a liberdade de expressão ou sobre a autonomia penal da produção simbólica, uma vez que abarca questões políticas, sociais e um importante jogo de forças existente entre os atores envolvidos. (PAZ et al., 2016).

Neste contexto, os grupos e os indivíduos podem se separar de acordo com impressões muito particulares, isolarem-se de uma normalidade sistêmica e padronizada, na qual tanto uns como os outros podem ser subversivos. Em relação às normas, esses podem transgredir ou subverter em relação aos pontos de vista. A subversão pode emanar de um sujeito ou de um coletivo que não se encaixa e não se afina em suas práticas com o que é esperado de uma sociedade e de sua atividade. E a partir de suas mudanças comportamentais pode influenciar transformações gradativas em todo o histórico registrado sobre algo, ou algum costume ou tradição. E a individualidade é que emerge nestes territórios, trazendo suas impressões e quebras paradigmáticas, observando-se também que um grupo pode ter suas marcas individuais.

[...] "a subjetividade [...] expressa-se infrapoliticamente, em vez de em uma política do público, a qual se situa facilmente na contestação pública. Legitimidade, autoridade, voz, sentido e visibilidade são negadas à subjetividade oposicionista". O (ideário) colonizado trava uma luta para se descolonizar em todos os níveis - pessoal, político, discursivo - demandando uma política de resistência rumo à liberdade - a própria individualidade. (LUGONES, 2014, p. 440 apud TIGRE; SACRAMENTO, 2015, p. 93). 
Neste sentido, individualidade é o que se pode ligar à ideia de quebra com a política geral dominante ou tradição preponderante. Individualidade, portanto, tem lacunas que se conectam ao conceito de subversão.

Michel Foucault, no entanto, associa o conceito de transgressão a esse caráter estruturalmente transformador quando utiliza a definição princípio de contestação. A transgressão assume então, como termo na percepção foucaultiana, sentidos aparentemente subversivos de que falávamos, quando esbarram na observação de Chauí: leis que foram feitas para serem transgredidas e não transformadas ou arruinadas. Então vemos os termos se atravessarem na produção bibliográfica de sentidos e da semântica dos mesmos. Cada autor trabalhará esse sentido, dado que, historicamente, muitas vezes transgressão e subversão se esbarrarão em dados momentos e que a subversão ultrapassará a transgressão impotente de transformar.

\begin{abstract}
São representativas na história da arte latino-americana as tensões entre a norma e a contravenção, a moralidade e a imoralidade, o clássico e o popular, o oficial e o extraoficial, o Novo e o Velho Mundo. Neste jogo de forças, observamos que a transgressão emerge de uma espécie de saturação diante de situações-limite, visto que a ação de transgredir põe em cena o extravasamento das relações, seja mediante um ímpeto novo de imaginação e criatividade, seja pela suspensão dos acontecimentos. Assim, a ideia de transgressão pode ser considerada como impulso de transformação em situações variadas, já que reacende o espírito crítico através daquilo que Blanchot chamou de princípio de contestação1 e que se define como um esforço de pensar e agir de um modo outro. Michel Foucault refere-se a esse princípio de contestação, em Blanchot, para ressaltar uma espécie de "prova do limite" Além disso, pode-se conferir a atmosfera desses posicionamentos nos próprios ensaios La condition critique, Le discours philosophique e Quelques remarques sur Sade. (PAZ et al., 2016).
\end{abstract}

Não quero classificar definitivamente as performances em que estive como subversivas, a não ser por seu sentido terminológico literal. Mas elas parecem seguir em uma direção contrária ao poder e às lógicas governamentais e políticas instauradas nos últimos tempos no país, uma precarização contínua desde 2014, com o advento do neoliberalismo mais radical. Como dito anteriormente, optei por utilizar o termo subversão deste modo, mas quero chamar atenção para o caráter subversivo de performances que, transgredindo ou não ordens, levam o pensamento a um nível transgressor no sentido a que Foucault remontou. Elas impactam na tentativa de transformar percepções dos estudantes de modo gradativo, bem como deixar que o leitor faça essa avaliação, com dois exemplos práticos em duas ocasiões de práticas performativas na escola, em que a repercussão apontava para uma turbulência maior; para um feito desestabilizador, que evoca transformações sistêmicas gerais constituintes da escola pública, de seus currículos e conteúdos, de gestão, colocando em cheque, em exposição e notoriedade as nossas posições como sujeitos excessivamente interventivos e passíveis de reações extremas.

Fazer algo controverso que confronte uma moral vigente há muitos anos é um aspecto que se acentua tremendamente quando se infiltra no território da educação. Isso só piora quando se trata de menores de idade. São duas barreiras de transformações que necessitam ser rompidas para que mudanças estruturais mais profundas comecem a dar vazão a um novo tipo de moralidade como produto do desenvolvi- 
mento social. Poderia ser revolucionário se não fosse local, e se a coibição não fosse esmagadora - as pessoas querem mudanças radicais, mas não conseguem. Poderia ser subversivo ou transgressor? Marilena Chauí e Foucault responderiam de modo híbrido essa questão, quando aquela dá ao sentido da palavra subversão uma problematização que este dá com suas limitações de temporalidade em Prefácio à Transgressão (TIGRE; SACRAMENTO, 2015).

Nas artes, tais atitudes foram vivenciadas por meio da crítica à normatividade, à hierarquia dos valores e à interdição; bem como pela constatação dos limites de nossa própria linguagem. Nessa linha, observamos o aparecimento de obras que perpassaram ao menos três formas transgressivas: a arte que ultrapassa as regras da arte, a arte que destrói os tabus e a arte de resistência política. Na América Latina, o encontro entre diversas culturas gerou, no que concerne às artes e às expressões culturais, um processo de mestiçagem e hibridização das formas. Estes eventos, marcados pela violência e por circunstâncias conflitantes de imposição/resistência e submissão/transgressão, são também reflexos dos confrontos que ocorreram durante o período da colonização. Nesse sentido, tais relações se caracterizaram pela aceitação, o rechaço e a incorporação de novos elementos que impulsionaram sincretismos. A partir desse ponto de vista, a transgressão pode ser considerada como fruto desses conflitos, principalmente quando relacionada com o processo de mestiçagem e com questões políticas ou morais. Como exemplo, poderíamos citar as inúmeras polêmicas em torno da representação de Virgens com traços mestiços ou a pintura A Carioca de Pedro Américo, que no final do século XIX, causou grandes discussões devido a seu grau de erotismo. (PAZ et al., 2016).

Uma ação cultural pode, então, possuir uma virulência transformadora e, dependentemente de seu contexto e repercussões, servir de mola propulsora para outras ações e para reflexões que tornam a realidade historicizada e ainda mais movediça.

Um primeiro exemplo simples que pode promover uma mudança de hábito e que a partir disso altere todo um costume de uma realidade local e vá se ampliando na passagem do tempo para os planos macros são os costumes ligados socialmente às definições de gênero. Estudantes de uma escola dominada completamente pelo bullying machista no passado, que antes não podiam dar qualquer sinal de fragilidade para a crítica atroz masculina, atualmente já têm confrontado essa estrutura. Cada vez mais um maior número faz questão de demonstrar quando são homossexuais ou transgêneros. E mais, meninos heterossexuais já não se importam em utilizar acessórios femininos. A lógica da periferia e de um contexto político homofóbico, transfóbico e adepto à censura e ao machismo ainda coíbe radicalmente as expressões, porém menos que nas décadas de 1980 e 1990. A performance com meninos de batom, realizada em 2018, buscou consolidar essa observação, sendo elaborada em conjunto durante uma aula a partir de uma conversa sobre moralismo e convencionalismo nas roupas e acessórios de uso pessoal. No dia seguinte, alguns estudantes do sexo masculino, heterossexuais inclusive, resolveram experimentar e vieram de batom. 


\section{EXPERIÊNCIAS}

Minhas primeiras experiências no campo e depois outras mais recentes começaram em 2013. Em 2014, enquanto professor da Educação Básica no Ensino Fundamental II e Médio, na Escola Estadual Professor Renato Braga, em uma periferia da Zona Sul da cidade de São Paulo, iniciei minhas experimentações na escola em todas essas séries, desde o sexto ano até a terceira série final do Ensino Médio, com foco central nesta última, por meio de ações que aos poucos se revelaram performativas. Tanto pelo caráter de eventualidade dos feitos e pela subjetividade expressiva que podia se notar nos estudantes, quanto pela natureza política do que estava sendo produzido e pelo que entendíamos acerca do meio de expressão identificado: um canal de reivindicação e uma forma de manifestação. Naquele momento, a criação em conjunto nos tempos e espaços propostos teve como disparadores os anseios e expectativas estudantis relacionados tanto as realidades locais e pessoais dos jovens em questão, em relação à escola, aos professores, a comunidade e mais amplamente a sociedade, quanto aos momentos políticos atrelados de grande repercussão midiática e cultural. O período era pós-manifestações de 2013 no Brasil, insurgência do MPL - Movimento Passe-Livre, que protestava contra o aumento da passagem dos transportes públicos em São Paulo, ações repreendidas drasticamente pela força de Estado da PM - a Polícia Militar, evento notório e a partir dele considera-se a eclosão em grandes atos por todo o país. Sentindo-se mobilizados, os estudantes sugeriram em conversas e debates informais em sala de aula sobre a possibilidade de se manifestarem politicamente a versar sobre a justiça social. E sobre como isso podia partir de atividades fomentadas na e pela própria escola. A reflexão também se deu porque os indivíduos do grupo identificavam problemas com a educação pública a nível nacional, e especialmente Estadual, em São Paulo - referente às suas próprias inserções históricas e reais.

Todos sabem que muitas escolas ainda hoje, em 2017, se encontram em condições de péssima infraestrutura, falta de água, recentemente de merenda, sobre a desvalorização dos professores da rede pública, etc. - e aqueles estudantes em 2013 percebiam a importância da liberdade de expressão e o quanto as linguagens e as artes poderiam lhes servir de instrumento para projetar suas vozes plurais, dúvidas e anseios, em busca de suprir necessidades públicas, subjetivas, e tendo em vista a ampliação e criação do que já entendiam por direitos e deveres na política e pelo que já pressupunham por espaço privado e espaço público.

Houve debate e nele discutimos durante algumas aulas sobre o que queríamos falar, sobre o momento delicado vivido e como construiríamos esses discursos de modo que todos fossem representados, a princípio, por questões inerentes ao grupo como um todo, a partir da escola e das questões sociais e políticas em voga. Decidimos então que falaríamos sobre a necessidade de expor um aspecto que os estudantes sentem como comum em suas vivências e em seus contextos específicos: a alienação. Ligados ao senso comum e levando em consideração a experiência concreta dos sujeitos, naquele momento entendíamos por alienação a forma anestesiante e dissimulada das instâncias políticas governamentais tratarem a população, "no paralelo": negligência do Estado com as necessidades fundamentais, entre as 
quais, a educação pública gratuita e de qualidade. Neste intento, pensamos em quais materiais poderíamos utilizar e de que formas poderíamos representar a alienação, isto é, o enrijecimento do pensamento crítico e a ideia anestesiante e sustentada pelo conformismo dos corpos dóceis (Foucault, 1975) mencionada anteriormente.

Elegi, a partir de uma inspiração de um dos grupos de Teatro Visual dos quais eu era integrante, a máscara neutra (Copeau, 2004) como recurso, e essa atividade consistia a princípio em: os estudantes cobrirem seus rostos com um pano branco, especificamente fraldas de pano.

A máscara neutra foi uma forma de metodologia utilizada por Jacques Copeau para corrigir vícios de movimentação dos atores e transformar o teatro vigente que segundo ele "estava impregnado pelo exibicionismo dos atores, monstros sagrados, e pelos vícios interpretativos de um teatro de 'mãos e rosto'" (Copeau apud Sachs, 2004 , p. 38), em busca de uma arte do espetáculo que saísse de seu instante meramente festivo e glamoroso para uma prática cênica de maior relevância técnica e também moral e ética. Para ele, este recurso potencializaria a precisão técnica do corpo e do movimento, ante o bloqueio dos vícios de expressão do rosto, ante o bloqueio parcial da visão e das iniciativas sem compromisso com o rigor da atuação.

Não se trata aqui de utilizar esse material somente para neutralizar a expressão desses estudantes em uma analogia entre alienação e expressão neutra, anestesiada e inerte, mas também de propiciar um estímulo sensorial do contato do material com o rosto, com a sensação de ver difusamente, de forma nebulosa, com a sensação claustrofóbica e sufocante que talvez, apenas talvez, tivesse relação com a realidade vivenciada: uma política de corrupção, exploração, negligência e de sufocamento da expressão pela repressão de Estado, e pela dissimulação dos valores na relação de direito público e ocultamento do descaso, em um cenário de reivindicação e de luta pela ampliação de direitos, característica que marca a democracia e o exercício da cidadania.

Após diversas ações expressivas de ocupação dos espaços no interior da escola com esse material, a máscara neutra, em ato performativo no intuito de representar, comunicar e expressar as sensações e vivências relatadas, frente ao objetivo de ampliar esses discursos poéticos e políticos construídos, envolvendo a comunidade e mais amplamente a sociedade, e utilizando ao mesmo tempo as ferramentas tecnológicas de nosso tempo, criei junto aos estudantes uma página no Facebook intitulada A Escola Pública é NOSSA, dentro da qual publicávamos nossos atos. Segue abaixo uma das postagens que reporta uma das primeiras ações feitas por aqueles estudantes naquele ano:

Hoje, dia 31 de março de 2014, o Professor Thiago Camacho e seus alunos da Escola Estadual entraram em ação com a performance "Indisciplinados", manifesto que teve intuito crítico com relação a negligência do Estado acerca da Educação, do sistema público de ensino / escolar, da pouca valorização de professores e alunos, estes últimos, filhos de trabalhadores. (A ESCOLA PÚBLICA É NOSSA, 2014). 
Figura 1 - Autor e um jovem integrante da ação. Escola Estadual Professor Renato Braga, São Paulo/SP, 2013.

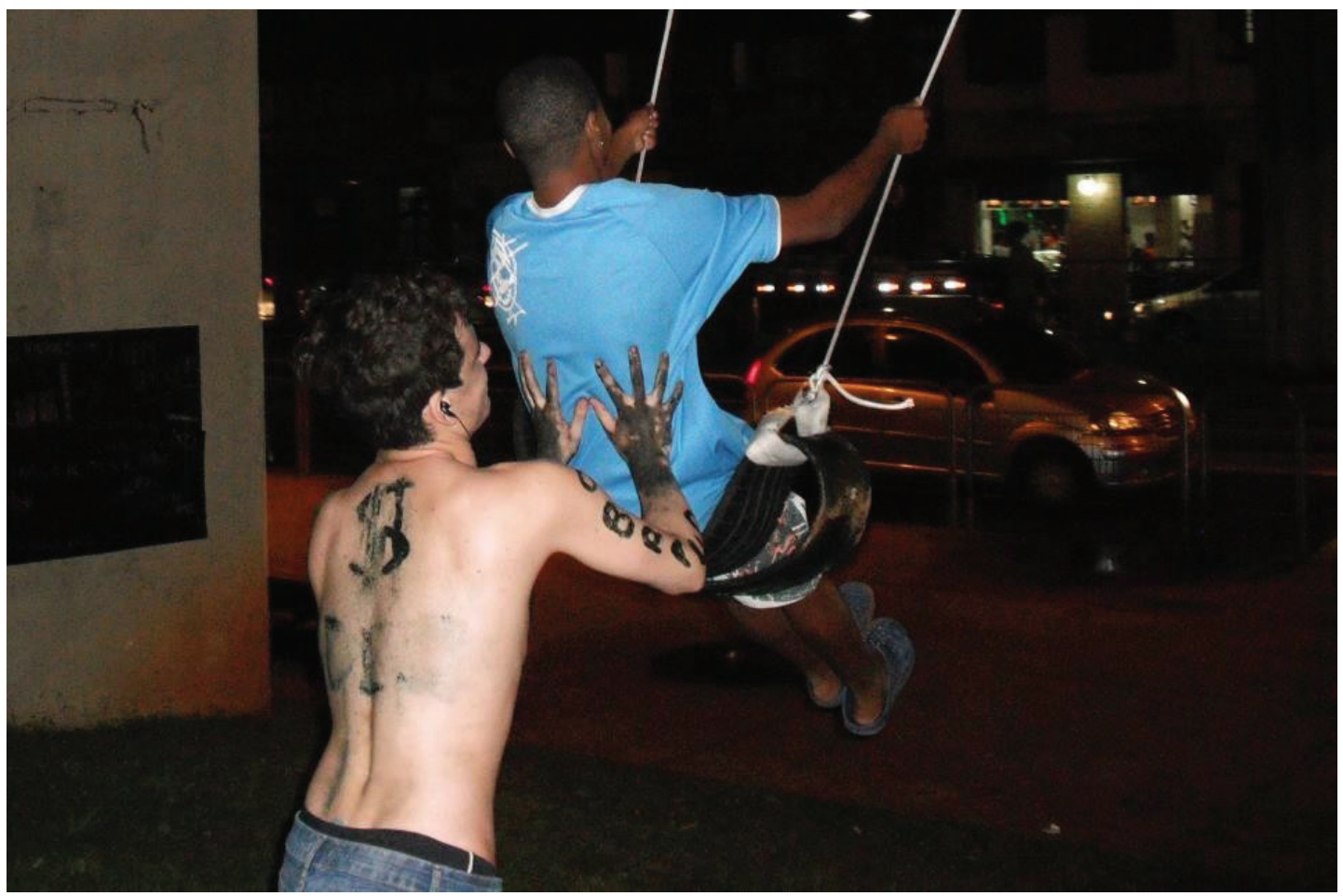

Fonte: Emerson Lisboa

Figura 2 - Autor e um jovem integrante da ação. Performance do Balanço. Gênese da ação. Escola Estadual Professor Renato Braga, São Paulo/SP, 2013

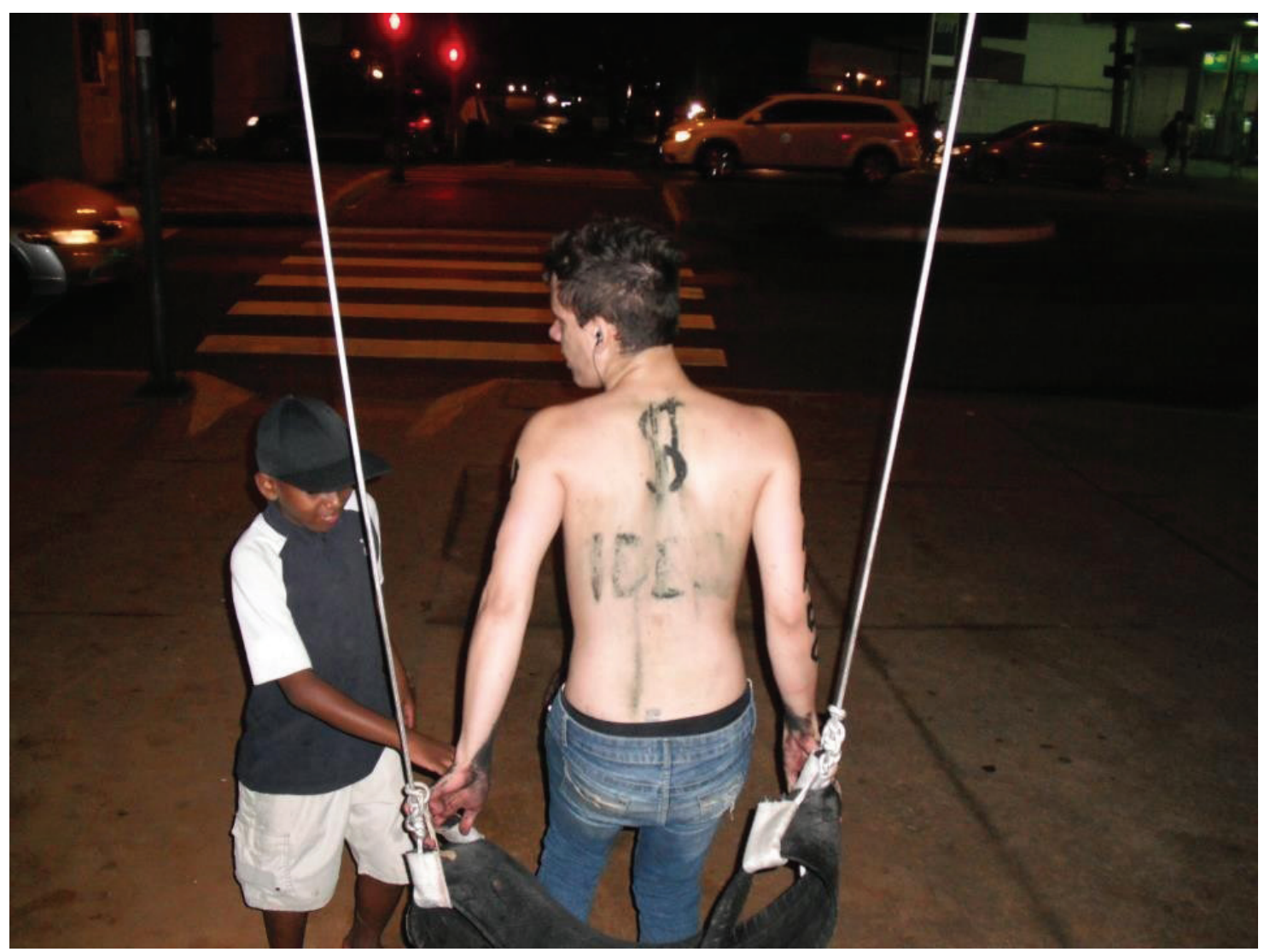

Fonte: Emerson Lisboa 
Figura 3 - Ato performativo com a máscara neutra. Escola Estadual Professor Renato Braga, São Paulo/SP, 2014.

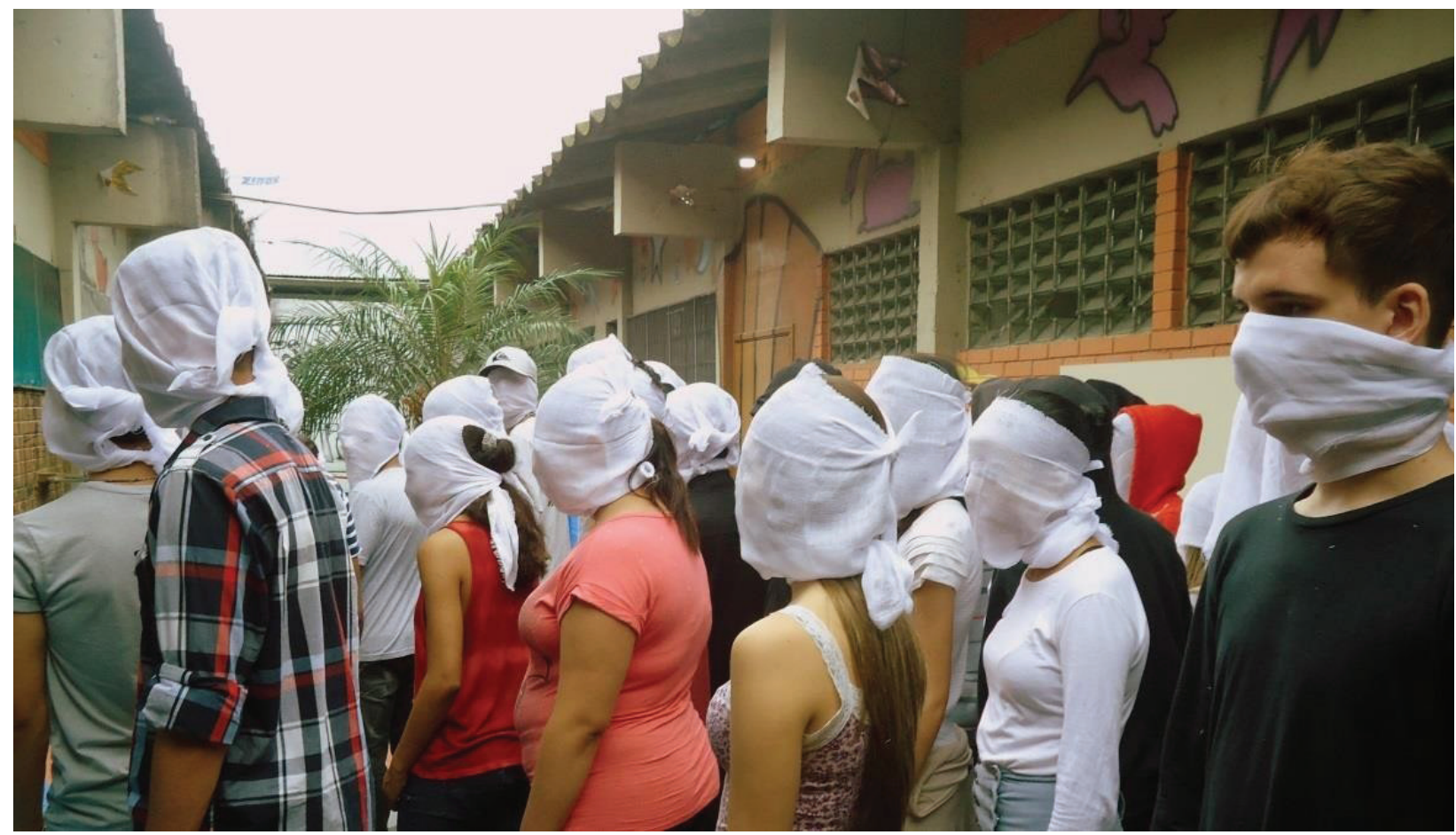

Fonte: Jared Mehmetof

Figura 4 - Ato performativo com a máscara neutra. Indisciplinados. São Paulo/SP, 2014

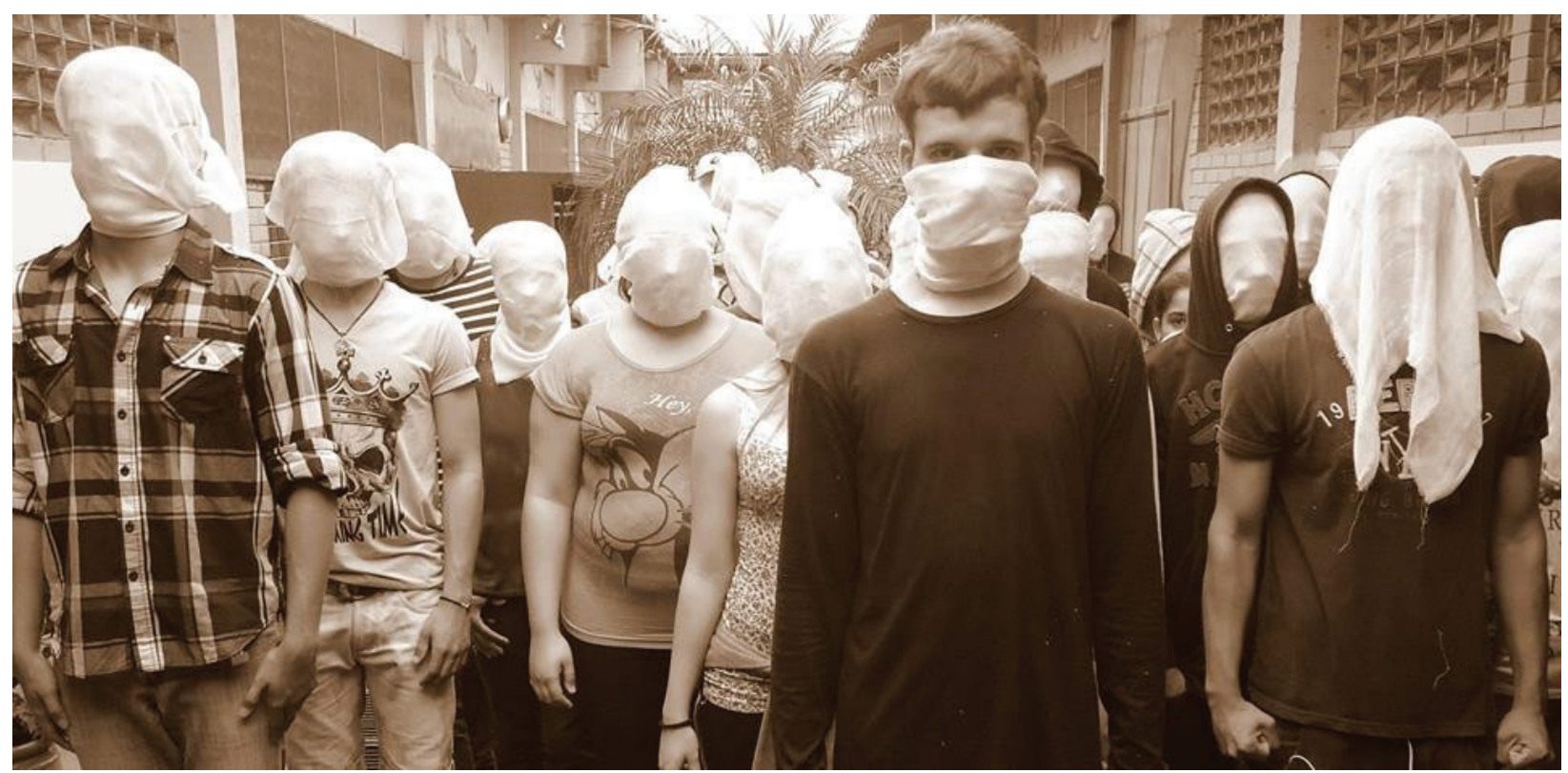

Fonte: Jared Mehmetof 


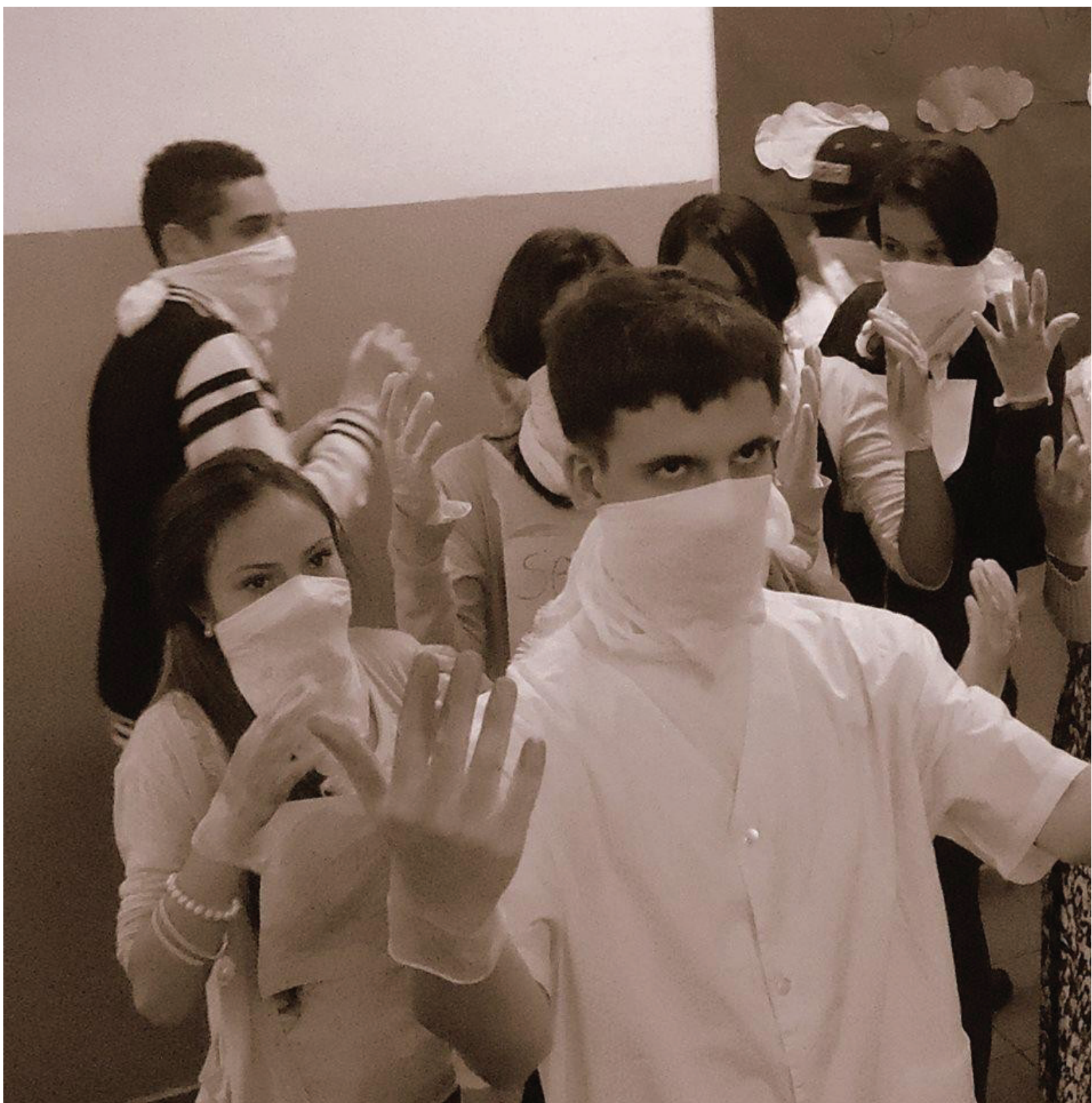

Fonte: Jared Mehmetof

Outro exemplo de ação performativa que promove rupturas e possibilidades de desestruturação das bases e regimentos foi a que ocorreu na E. E. Prof. Renato Braga em 2014, quando os estudantes resolveram protestar contra a polícia da Ronda escolar que, na entrada da escola, estava lhes dando tapinhas na cabeça e os xingando de nomes chulos, tais como "viadinhos" entre outros. Os estudantes se colocaram ao redor da escola com os olhos roxos, como se tivessem apanhado e utilizaram as máscaras neutras para deflagrar a neblina sob o olhar da população, uma visão turva que a impede de ver a realidade de desmontes públicos e coibição da liberdade de expressão (o que de fato aconteceu), com cartazes onde se lia "Resolveu bater em menor PM?".

Ao serem questionados sobre quem tinha organizado o evento, responderam que havia sido o professor Thiago Camacho Teixeira. Fui chamado e fiquei sozinho na 
sala da direção com três PMs e o vice-diretor Ney Alves. Uma das PMs, em pé, questionou-me enquanto eu estava sentado (um primeiro desnível): "por que você está se manifestando contra a polícia se a gente está aqui para defendê-lo?". Ela também me disse algo que dava para pressupor que iria me processar por estar incitando menores de idade a subverterem uma ordem. "O senhor vai encontrar problemas legais em incentivar menores de idade a se manifestarem contra uma instituição de segurança pública. Se continuar com isso terá problemas.", ela me disse. Apesar de relatar o que estava acontecendo, os possíveis abusos dos quais os estudantes reclamavam recorrentemente, os policias presentes negaram que isso tivesse acontecido. A partir disso decidi recuar e não continuei a ação. Achei o interrogatório um tanto ameaçador e não quis correr mais riscos. Mudei a estratégia, para ser mais sutil.

Mais um exemplo recente que também caminhou para um embate foi neste ano, 2019, quando, em uma mostra cultural, uma vídeo-performance que deveria ser instalada na E. E. República do Panamá foi cortada no evento. A atual coordenadora, chamada Roseli, disse que os pais reclamariam de ver seus filhos se afogando em uma bacia com água e que não aceitariam uma imagem-intervenção pesada assim. Expliquei o contexto, que os estudantes retratavam metáforas sobre o período da ditadura fazendo um paralelo com o período atual, sem citar nomes, sem partidarismo, mesmo assim o vídeo foi vetado da mostra.

Outra cena também vetada foi uma performance presencial em que os estudantes encheriam uma camisinha de ar até estourar e utilizariam camisetas onde se lia 'Truvada, prep, ou pep' - as profilaxias que previnem a infecção pelo vírus HIV. Consideraram a cena e tema inadequados para a idade de 14 anos. Impróprio por que, se em uma série anterior havia uma menina grávida aos 13? São perguntas como essa que modos subversivos de enfrentamento expressivo nos fazem colocar, as quais a performance discute de forma eficiente porque recorre a símbolos e imagens que perturbam a estabilidade conformada. Em um local onde não se pode discutir identidade de gênero sem que a confusão esteja armada, inclusive com ameaças de cunho jurídico, ampliar imageticamente reflexões sobre sexualidade na adolescência passa a ser algo imoral para a ideologia dominante.

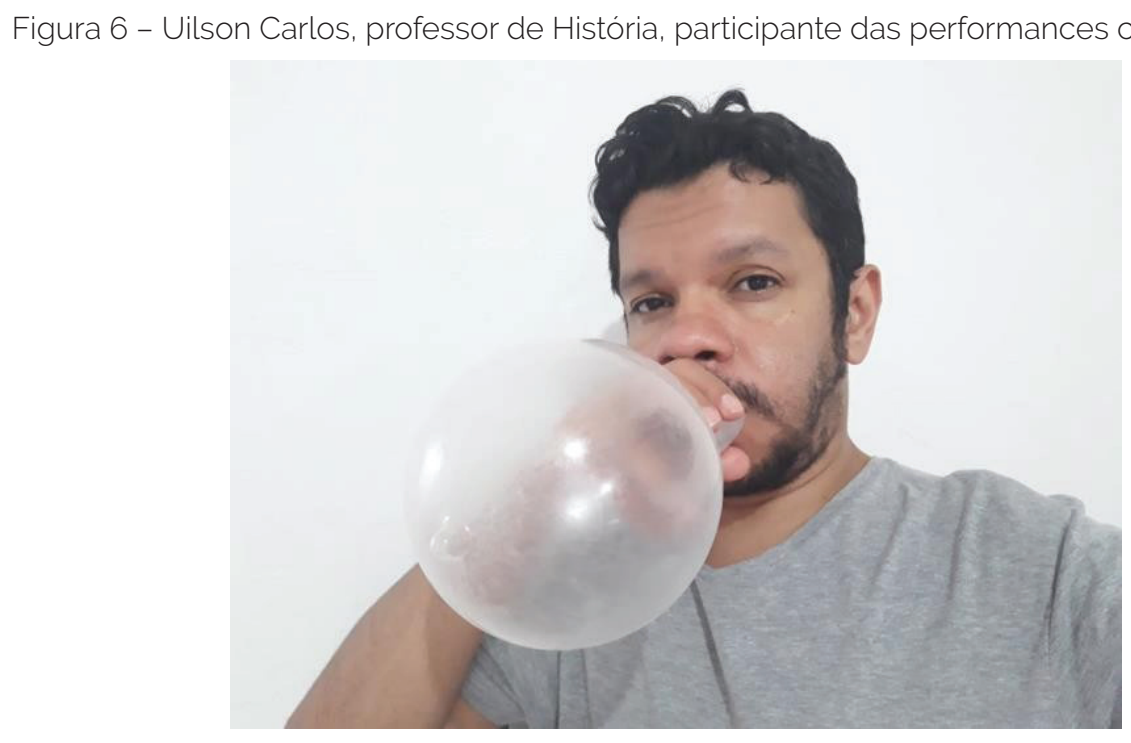

Fonte: Arquivo pessoal do autor 


\section{CONCLUSÃO}

A performance, como um ato radicalizado de liberdade de expressão, está sendo coibida da forma minuciosa, por meio dos poderes gerais, dos espalhados e das micropolíticas, até a forma mais genérica, advinda da macroestrutura política (governo e poder de Estado) e do advento sistêmico do neoliberalismo, desde 2014 até então, do governo do presidente Jair Messias Bolsonaro.

Todos os comentários e repercussões sobre as ações performativas na Escola Pública podem ser encontradas na página do Facebook A Escola Pública é NOSSA, de minha autoria. Lá, encontram-se depoimentos de estudantes, professores, comunidade escolar e local, sobre as percepções de encolhimento da liberdade de expressão no espaço público.

Como artista, antiartista, proponente de ações culturais ou educador, tenho as trocas em meio à criação coletiva e à expressão plural da diversidade constituinte da sala de aula, dos espaços das comunidades escolar e local, como possibilidades transformadoras microfísicas e políticas, com vistas a reverberações mais amplas na sociedade em geral, partindo do ato criativo em performance e outras ações artísticas e culturais que são canais os quais permitem verificar como percebermos que um caminho pode se expandir a partir da pluralidade, da diversidade e da democracia, contra a violência do totalitarismo ideológico. A meu ver e a de meus parceiros de atividade, a performance, que herda da modernidade a subversão, pode formar e ajudar no desenvolvimento global ou em torno da possibilidade de comunicar, vivenciar mais profundamente as experiências que trazem ensinamentos e construções que somente elas mesmas poderiam trazer em contextos específicos.

Performar é de todo modo interagir subvertendo sistemas artísticos, com sentidos diversos da transgressão. Isso atravessa o espectador de um jeito diferente, envolvendo representação e presentificação. E quando esta ação está disponível como modo educativo e alternativa pedagógica, gera a experiência que tanto interessa no processo de ensino-aprendizagem nas abordagens sociais, poéticas e político-culturais dos espaços escolares, frente à possibilidade da comunicação.

Portanto, performar é subverter, inclusive contra as formas e contra esse poder. Não se pode esperar que o performer, artista ou não artista, diga além do que sente e vive. Mesmo que sua experiência caia como uma bomba e apareça como um atentando às crenças pessoais de alguém, ele também tem os seus ideários, que são aquilo de mais verdadeiro, autêntico e expressivo que poderá comunicar. O que nos leva a questionar se haverá democracia mais plena e consolidada do que a que permite que se fale exatamente o que se pensa por meio da arte ou de qualquer outro. ${ }^{2}$

\footnotetext{
2 Texto revisado pelo autor, licenciado em Letras - Português, Inglês e Literatura (UNIP). E-mail: thiagocamacho@usp.br. Revisão técnica: Samuel Estevão Vieira da Silva, graduado em Ciências Sociais (UNESP) e mestrando em Filosofia (UFSCar). E-mail: samuelestevaovs@gmail.com.
} 


\section{REFERÊNCIAS BIBLIOGRÁFICAS}

ANDRÉ, Carminda Mendes. Teatro pós-dramático na escola: Inventando espaços: estudos sobre as condições do ensino do teatro em sala de aula. São Paulo: Editora Unesp, 2011.

A ESCOLA PÚBLICA É NOSSA. Hoje, dia 31 de Março de 2014, o Professor Thiago Camacho e seus alunos da Escola Estadual entraram em ação com a performance "Indisciplinados". São Paulo, 31 mar. 2014. Facebook: ProfessorThiagoCamacho. Disponivel em: https://www.facebook.com/ProfessorThiagoCamacho/photos /a.455456264585172/456117827852349/?type=3\&theater. Acesso em: 16 jun. 2019.

BRASIL. Lei $n$ ㅇ 9.394, de 20 de dezembro de 1996. Estabelece as diretrizes e bases da educação nacional. Disponível em: http://www.planalto.gov.br/ccivil_03/LEIS/ L9394.htm. Acesso em: 10 jun. 2017.

BRUM, Eliane. "Fui morto na internet como se fosse um zumbi da série The Walking Dead". El País, 12 fev. 2018. Disponível em: https://brasil.elpais.com/brasil/2018/02/12/opinion/1518444964_080093.html. Acesso em: 16 jun. 2019.

CANTON, Katia. Da Política às Micropolíticas. Coleção Temas da arte contemporânea. São Paulo: WMF Martins Fontes Ltda., v. 1, 2009d.

CANTON, Katia. Do Moderno ao Contemporâneo. Coleção Temas da arte contemporânea. São Paulo: WMF Martins Fontes Ltda., v. 1, 2009 b.

CANTON, Katia. Temas da arte contemporânea. Coleção Temas da arte contemporânea. São Paulo: WMF Martins Fontes Ltda., v. 6, 2009a.

CHAUÍ, Marilena. O que é ideologia. São Paulo: Brasiliense, 2008.

CHAUÍ, Marilena. Sociedade brasileira: violência e autoritarismo por todos os lados. Revista Cult, n. 209, fev. 2016. Disponível em: http://revistacult.uol.com.br/ home/2016/02/sociedade-brasileira-violencia-e-autoritarismo-por-todos-os-lados/\#respond. Acesso em: 20 jul. 2017.

COPEAU, Jacques. Reflexiones de um comediante sobre "La paradoja", de Diderot. Buenos Aires: Editorial La Pleyade, 1929.

CORREIA, Pedro Luís Lopes Pais. Arte e tecnologia: estratégias de subversão e transgressão. Aveiro, 2010. Disponível em:

https://ria.ua.pt/bitstream/10773/1182/1/2010001973.pdf. Acesso em: 20 jul. 2017.

FOUCAULT, Michel. Corpos dóceis. In: Vigiar e Punir. Petrópolis: Vozes, 1975.

FREIRE, Paulo. Pedagogia da autonomia. São Paulo: Paz e Terra, 2011.

LEHMANN, H-T. Teatro Pós-Dramático e Teatro Político. Sala Preta 3. USP, São Paulo, 
v. 3, p. 9-19, 2003.

MARTINS, Leonardo. A cada dia, ao menos 2 professores são agredidos em escolas estaduais em SP. UOL, São Paulo, 22 ago. 2019. Disponível em: https://educacao.uol.com.br/noticias/2019/08/22/a-cada-dia-ao-menos-2-professores-sao-agredidos-em-escolas-estaduais-em-sp.htm. Acesso em: 23 ago. 2019.

MKS, Guti. Priscilla Toscano quebra o silêncio e diz que críticas por defecar na rua são preconceito. Blasting News Brasil, 4 set. 2016. Disponível em: https://br.blastingnews.com/brasil/2016/09/priscilla-toscano-quebra-o-silencio-e-diz-que-criticas-por-defecar-na-rua-sao-preconceito-001098551.html. Acesso em: 16 jun. 2019.

PAZ, G. et al. Arte Ogie. Transgressão das artes/Transgressão nas artes. França, n. 8, 2016. Disponível em: https://journals.openedition.org/artelogie/623\#ftn1. Acesso em: 10 jun. 2017.

SALDAÑA, Paulo; FARIA, Flávia. Entenda as polêmicas sobre Escola sem Partido e gênero na educação. Folha de S. Paulo, São Paulo, 23 out. 2018. Disponível em: https:// www1.folha.uol.com.br/educacao/2018/10/entenda-as-polemicas-sobre-escola-sem-partido-e-genero-na-educacao.shtml. Acesso em: 5 mar. 2019.

SCHILLING, Voltaire. A Semana de Arte Moderna de 1922. Terra. Disponível em: https://www.terra.com.br/noticias/educacao/historia/a-semana-de-arte-moderna-de-1922,200823d6c76da310VgnCLD200000bbcceb0aRCRD.html. Acesso em 16 jun. 2019.

TIGRE, M. P.; SACRAMENTO, S. M. P. Identidade de Gênero em Subversão: Niketche, de Paulina Chiziane. Litterata: Revista do Centro de Estudos Hélio Simões, v. 3, n. 2, 2015. Disponível em: http://periodicos.uesc.br/index.php/litterata/article/view/855. Acesso em: 10 jun. 2017.

TOKARNIA, Mariana. Professores e organizações querem arte obrigatória no ensino médio. Agência Brasil, Brasília, 22 ago. 2018. Disponível em: http://agenciabrasil. ebc.com.br/educacao/noticia/2018-08/professores-e-organizacoes-querem-arte-obrigatoria-no-ensino-medio. Acesso em: 25 ago. 2018.

TOSCANO, Priscila. Vídeo-performance do Laboratório do Vale. 2017. Disponível em: https://vimeo.com/182791062. Acesso em: 10 jun. 2017. 